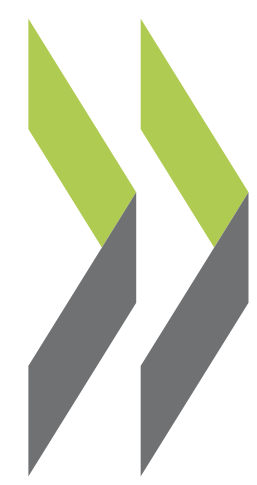

CELE Exchange, Centre for Effective Learning Environments 2009/08

\title{
Monitoring the Quality of School Buildings in Belgium's Flemish Community
}

\section{Geert Leemans}

https://dx.doi.org/10.1787/220808504374 


\section{Monitoring the Quality of School Buildings in Belgium's Flemish Community}

By Geert Leemans, AGIOn, Belgium

In the course of 2008, the Flemish Agency for Infrastructure in Education (AGIOn) evaluated the quality of school buildings in Flanders using a monitoring system based on international experience. The results showed that most school buildings satisfy the basic requirements of habitability and safety, but they often fall short when it comes to the new pedagogical and social challenges of the $21^{\text {st }}$ century.

\section{NEW CHALLENGES FOR SCHOOL BUILDING IN FLANDERS}

In recent years, large-scale investment operations in school buildings have been mounted in many countries, like the Design-Build-Finance-Maintain (DBFM) project in the Flanders region of Belgium, which provides for building and renovating more than 200 schools via Private Finance Initiatives (PFI). These investment initiatives have breathed new life into the debate on how schools should be built, and frequently result in a new vision of school buildings for the $21^{\text {st }}$ century.

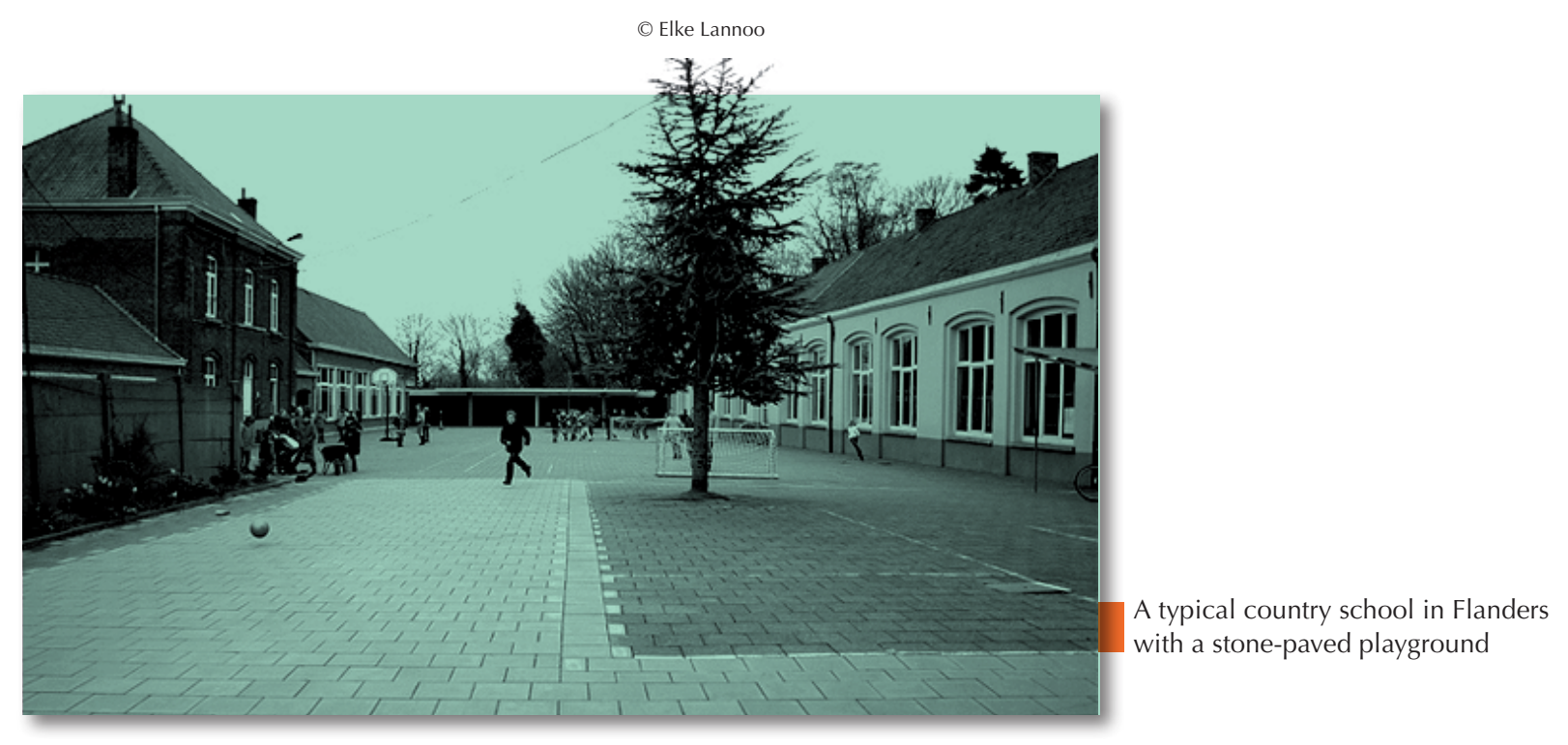

More demands are made on today's school buildings than in the past. Developments in education and society - such as needs related to sustainability and environmental friendliness, information and communication technologies (ICT) in the classroom, school use by the community, inclusive education or changing pedagogical methods - have led to new ideas about what is considered a good contemporary school building. 


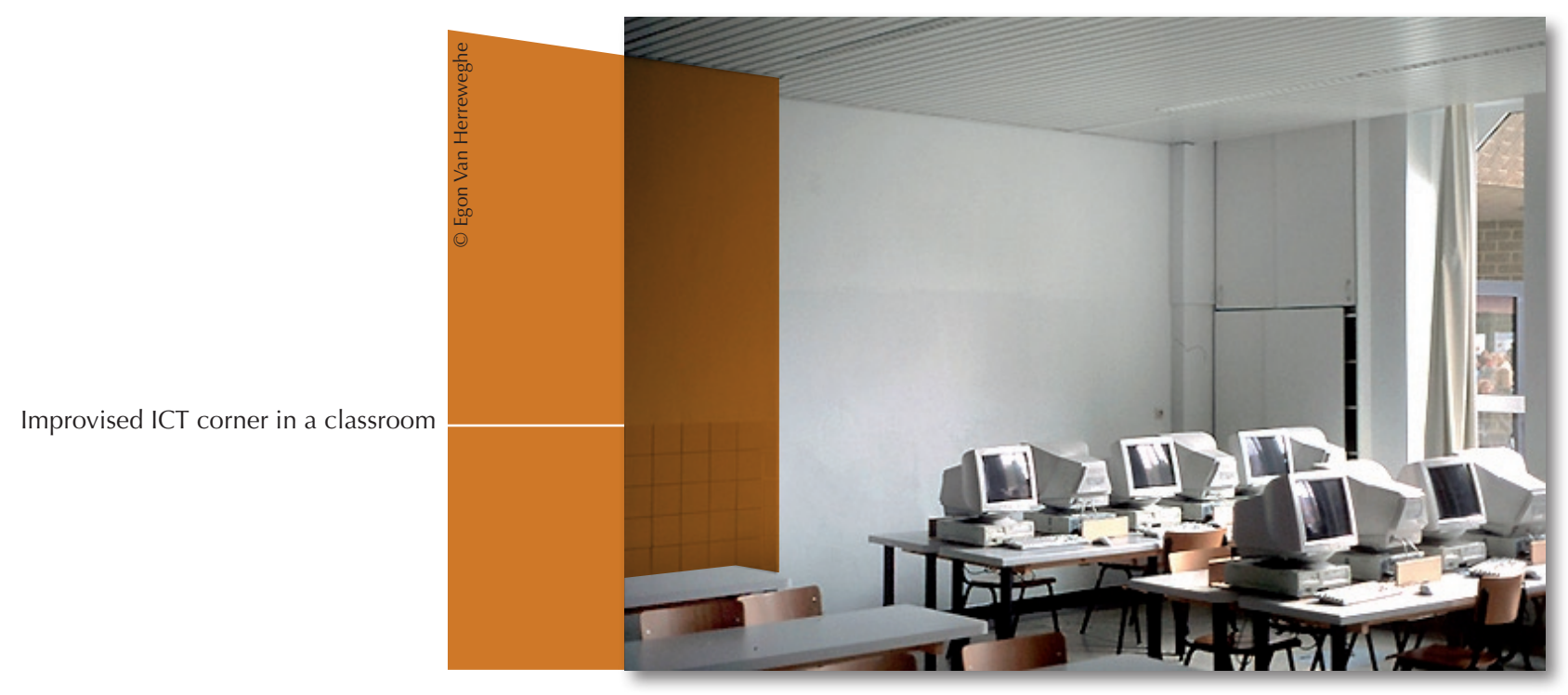

AGIOn, the agency that subsidises Flemish school buildings, has formulated some basic principles for quality school buildings in Flanders and set them out in strategic policy objectives. Contemporary school buildings should, first of all, be functional and sustainable. They should be safe, comfortable, easy to maintain and easily accessible. They should support the school's pedagogical project, provide a stimulating learning environment and be suitable for flexible and multifunctional use. In addition, they should be sustainable in various ways: they should have an open relationship with the surrounding community, they should have lasting architectural value, they should be economically sustainable, with a good cost-return ratio for construction and management and, finally, they should be environmentally friendly in terms of building materials, energy and water consumption.

A school building monitoring system was designed to check the extent to which schools in Flanders meet these standards and their corresponding policy objectives.

\section{THE DEVELOPMENT OF THE MONITORING SYSTEM}

To successfully evaluate policy requires an assessment instrument which follows the logic of the management and policy cycle and is made up of a number of basic components in a cyclical sequence. The policy cycle shows that within a larger educational and societal context, policy formulates a number of goals to aim for regarding school buildings and provides the inputs (e.g. investment budgets, human resources, norms and regulations) necessary to meet them. The agency can then carry out a number of processes (e.g. file handling, PFI-supervision, providing design and planning support) generating outputs (e.g. subsidies granted to schools, PFI investments, design and planning advice), which should, in the end, lead to desired outcomes in the schools - in this case achieving better quality in school buildings. (See Figure 1.)

In the framework of its policy evaluation, AGIOn was mainly interested in the outputs that have been produced and the effects of policy (indicated in the green box in Figure 1). To measure these outputs and effects, the agency created a monitoring system, by which indicators are used to describe the effectiveness of policy. These indicators require systematic and recurrent data collection. 


\section{Figure 1 THE POLICY CYCLE}

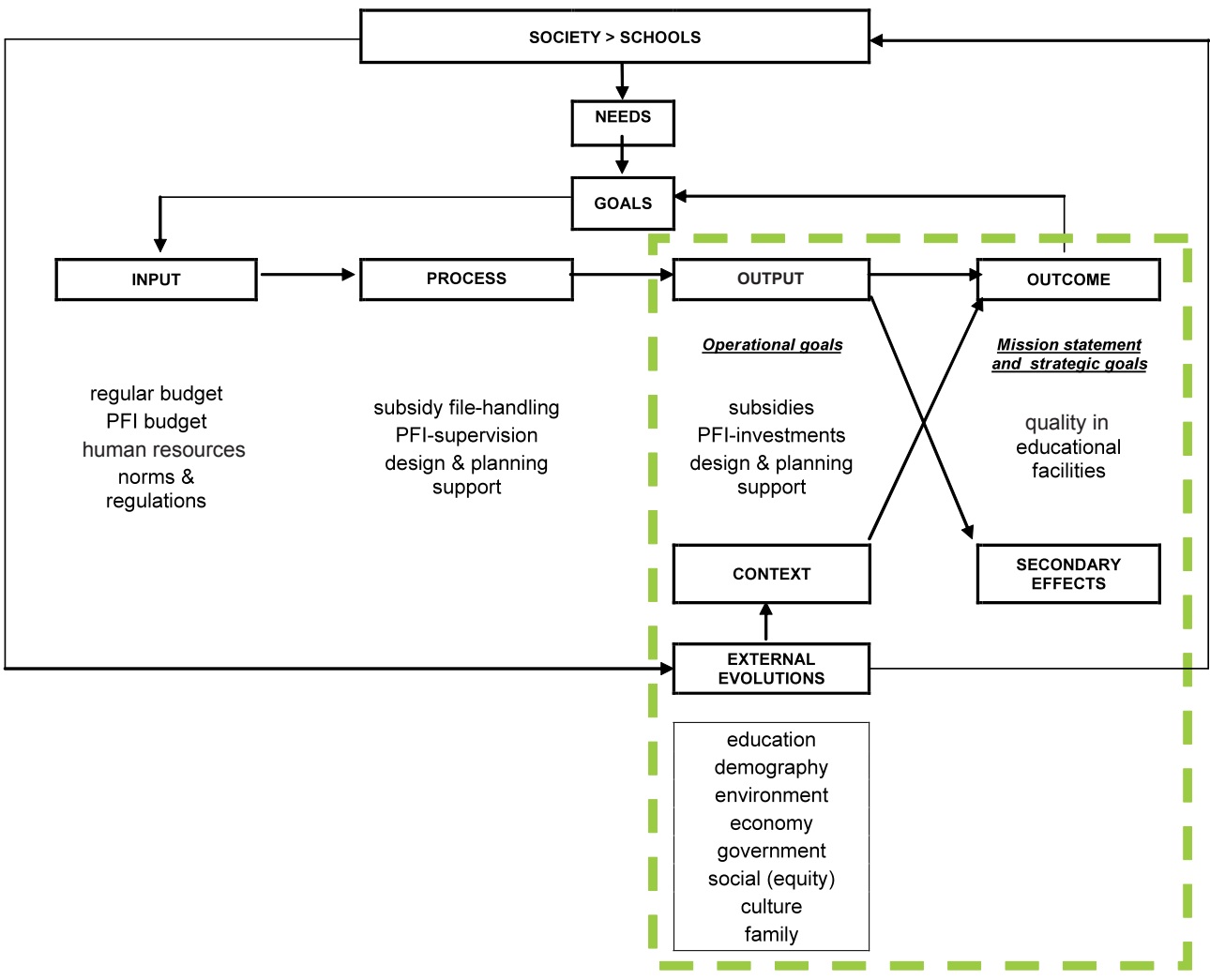

To ensure that the right indicators were selected to assess the quality of school buildings, the notion of quality, as it exists in Flemish school building policy, was tested from four perspectives, namely:

(1) general ideas on the architectural quality of buildings emerging from scientific and governmental publications about architectural quality and Post Occupancy Evaluations;

(2) recent opinions on good school architecture from international think tanks and organisations such as the American DesignShare or the British Commission for Architecture and the Built Environment;

(3) current work on quality in school buildings by the OECD Centre for Effective Learning Environments (CELE), especially the "Evaluating Quality in Educational Spaces" project(seeCELEOrganising Framework on Evaluating Quality in Educational Spaces at www.oecd.org/edu/facilities/evaluatingquality;

(4) criteria used in existing surveys and evaluation instruments to assess the quality of school buildings. Over 30 evaluation scales and questionnaires were examined, from which a common set of descriptive and quality indicators were selected.

This review produced a useful list of quality indicators. Some relate to the habitability, safety and hygiene of school buildings - the basic requirements that school buildings must meet for teaching to be carried out under acceptable conditions. Other indicators include criteria linked to the new $21^{\text {st }}$ century challenges facing school buildings in terms of sustainability, the changing social role of schools, and recent evolutions in pedagogy and teaching methods.

The statistics used for the indicators were collected from all the schools in Flanders via an online survey carried out early in 2008. In the survey, schools were asked to assess their building using a large number 
of criteria relating to diverse aspects of quality including, of course, recent $21^{\text {st }}$ century challenges. In addition to the quality of the buildings, attention was given to more descriptive information, such as building management and the age and surface area of the school buildings. Usable information on 3618 school sites, i.e. some $60 \%$ of the total, was collected.

\section{RESULTS FROM THE SCHOOL BUILDING SURVEY}

The survey's most important finding is that the quality of the majority of Flemish school buildings is adequate in terms of basic conditions of comfort, the state and safety; thus pupils and teachers are offered a certain basic quality as far as educational accommodation is concerned. But AGIOn also found that a minority of school buildings, $7 \%$ of the total, do not meet these basic standards. The most urgent problems therefore reside in this group.

When it comes to quality aspects associated with $21^{\text {st }}$ century challenges for school infrastructure, however, school buildings are far more often deficient. Twenty-six percent clearly cannot offer these new conditions, while only $21 \%$ definitely can. Some figures from the survey illustrate this (see Figure 2 ).

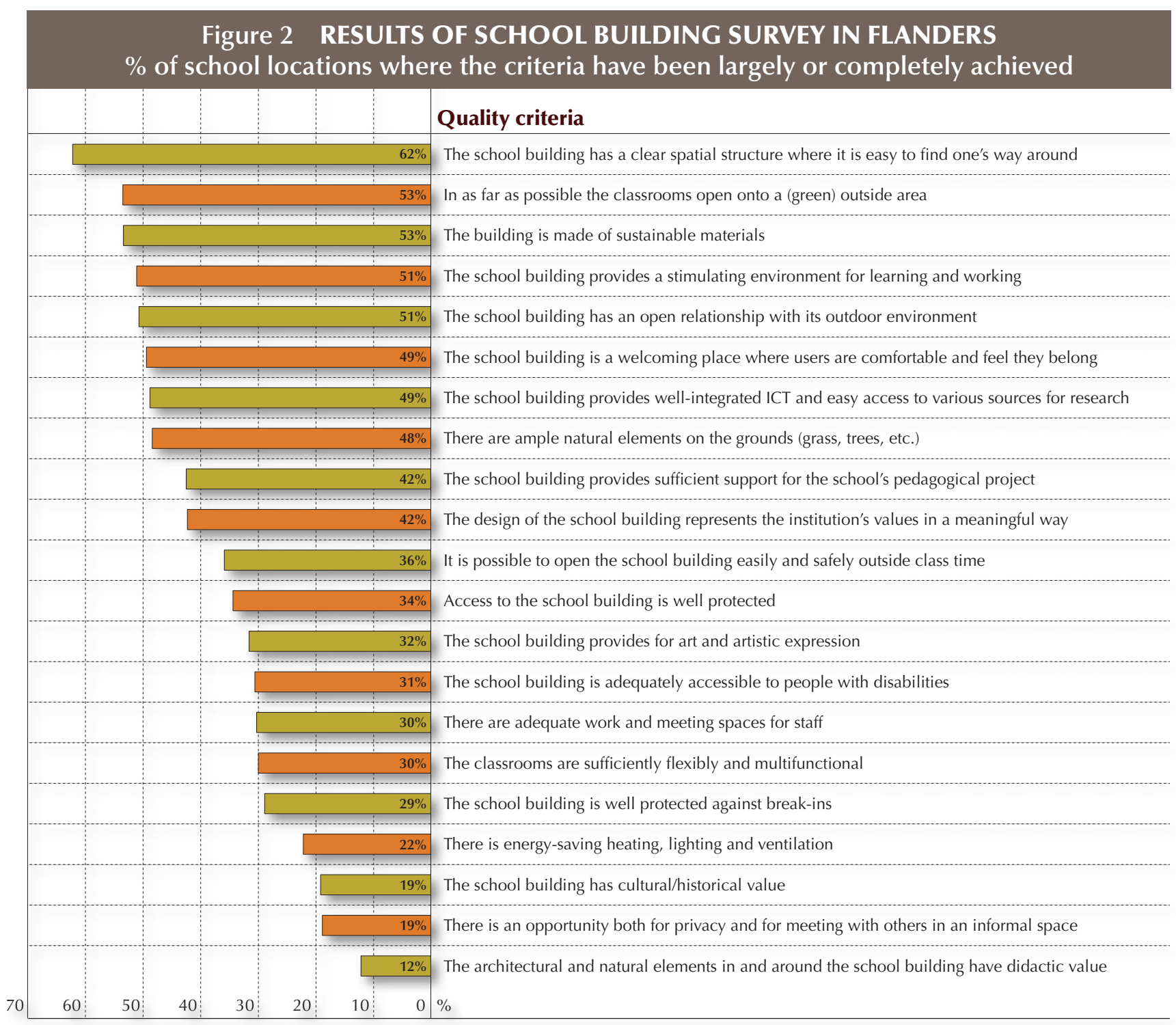


Concerning the building size, the survey found that, on average, there is a shortage of educational space in Flanders. At $32 \%$ of the sites, the school buildings are judged too small. Besides a lack of traditional classrooms, more support areas are needed, such as libraries or multi-media centres, relaxation spaces, staff rooms and multifunctional halls. The lack of space is most marked in the Brussels-Capital Region.

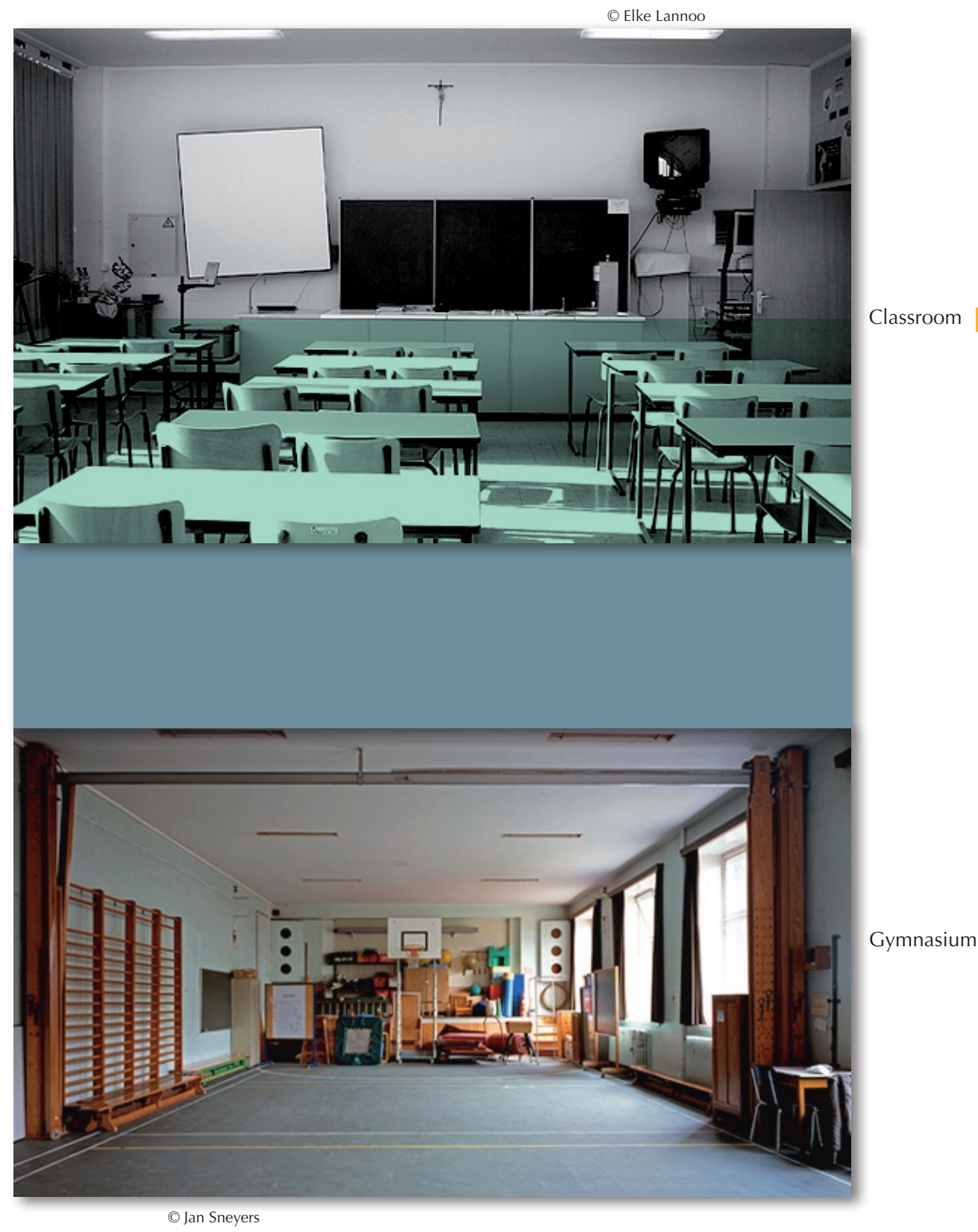

AGIOn discovered that the problem of school buildings exists to a greater or lesser extent in all Flanders' educational networks and at all levels of education. While $21 \%$ of school buildings were evaluated as inadequately usable, 53\% are adequately usable. The differences in quality and the problems linked to them are, in fact, related to the problem of poverty. School buildings located in poor, often inner-city, neighbourhoods were generally assessed as worse than the school buildings located in richer areas. 
Besides the quality of the buildings themselves, the survey addressed the process of realising new school building projects. It showed that school boards are generally given sufficient opportunities to participate in new building projects. In addition, in most cases there was provision for a well thought out building programme to be drawn up beforehand. Most school boards also received the advice they needed with regard to planning, design and financial matters. The opportunity to evaluate the project at fixed intervals and to fine-tune it was provided in most cases as well. Two conditions were met to a far lesser extent: for only $51 \%$ of new building or renovation projects, a procedure to select architects took place and, in general, there were limited opportunities for teachers, pupils, cleaning staff, parents and local residents to participate in the planning of the building.

Regarding the management of the buildings, the survey results showed that most schools have a prevention plan or a policy note on health, safety and the environment. However, a master plan setting out a school's long-term policy on infrastructure was available at only $42 \%$ of the sites. Gas is the most commonly used source of energy for heating Flemish school buildings (used at $74 \%$ of the sites), but fuel oil is still used as the energy source for heating at $42 \%$ of the sites. Alternative, environmentally friendly energy sources are very rarely used for heating buildings.

Findings on the use of school buildings were positive: rooms are empty on only $14 \%$ of the sites. In most cases, these are small parts of the building and the reason for them standing empty is often the fact that the rooms are no longer suitable for teaching. The buildings and classrooms at $59 \%$ of the sites are also used outside of normal school hours; this extracurricular use is to a large extent linked to the buildings' capacity to be made accessible in an easy and safe manner. In most cases, extracurricular use of school buildings occurs on a regular basis.

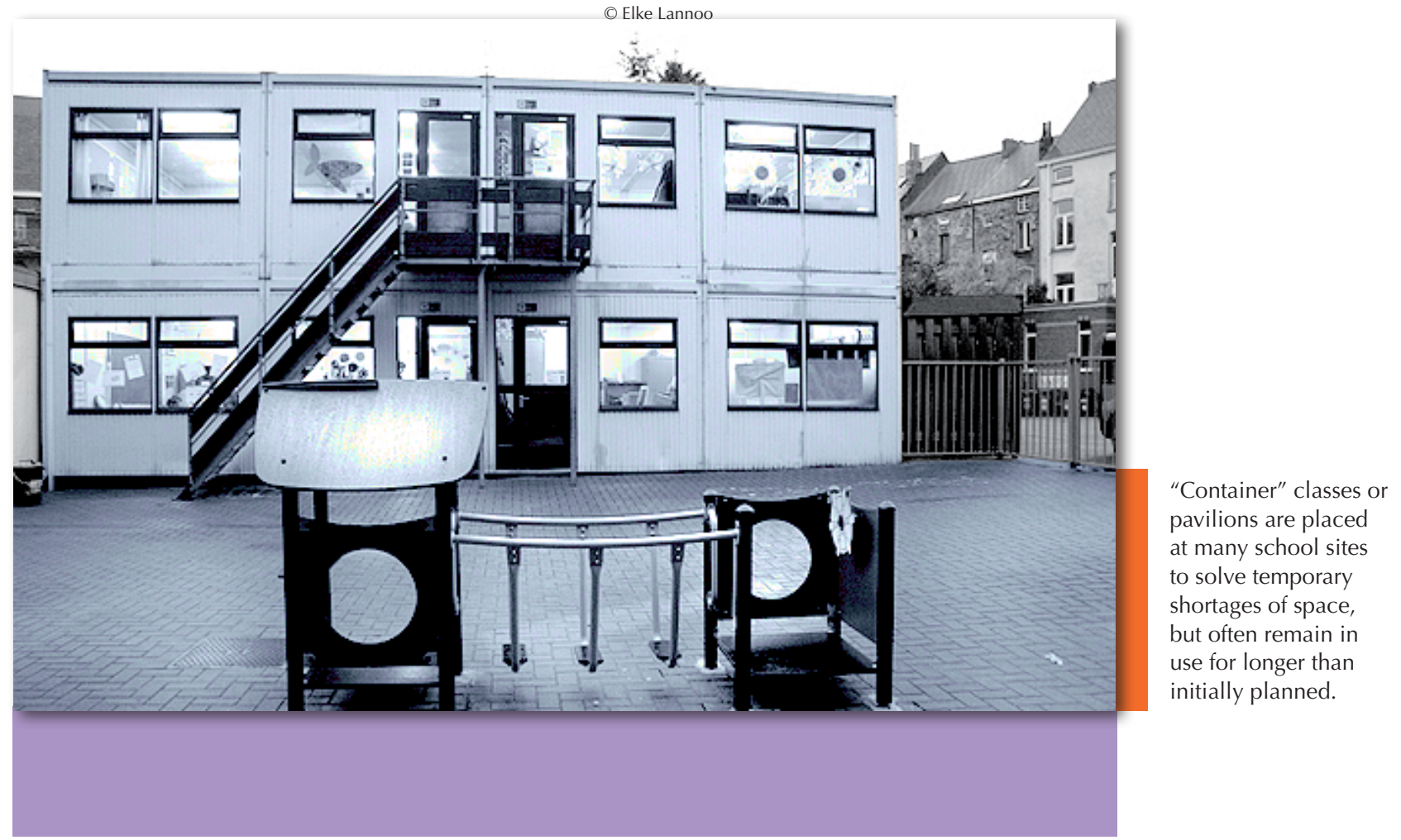




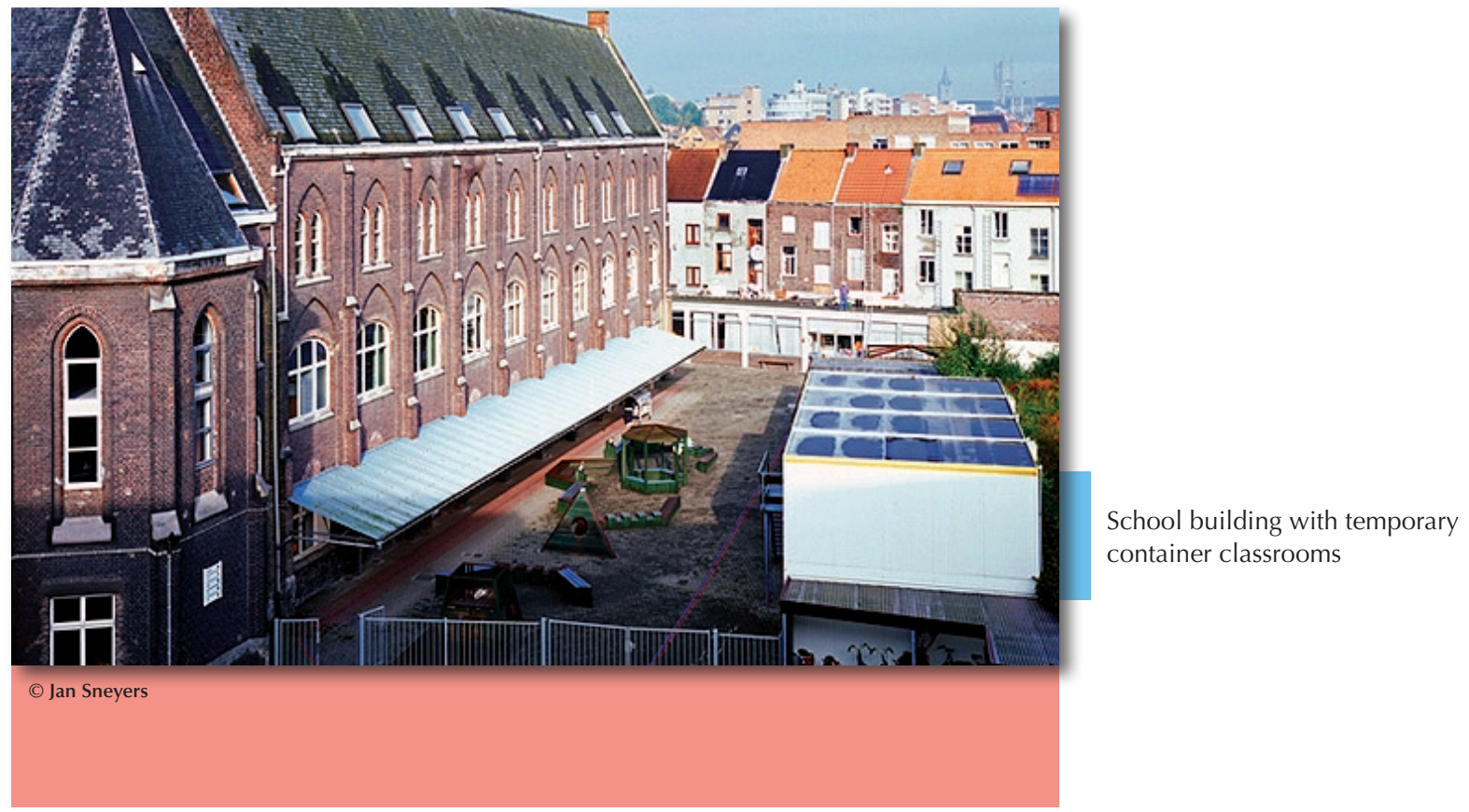

\section{CONCLUSION}

After many years of underinvestment and a policy aimed mainly at alleviating the greatest need, Flanders is now faced with the important challenge of increasing its stock of good quality school buildings. Recent initiatives, like an increase in the regular budgets for school building, the DBFM project or extra investments in rational energy use, are already a step in the right direction. But the survey shows that the need for quality buildings and additional financial resources still remains considerable in Flanders. This requires a sustained investment policy whose leitmotif is quality, innovation, and sound planning and design support for the schools.

For more information, contact:

Geert Leemans

AGIOn (Flemish Agency for Infrastructure in Education)

Koningsstraat 94

1000 Brussels

Belgium

E-mail: Geert.leemans@agion.be

www.agion.be 


\section{ORGANISATION FOR ECONOMIC CO-OPERATION AND DEVELOPMENT}

The OECD is a unique forum where the governments of 30 democracies work together to address the economic, social and environmental challenges of globalisation. The OECD is also at the forefront of efforts to understand and to help governments respond to new developments and concerns, such as corporate governance, the information economy and the challenges of an ageing population. The Organisation provides a setting where governments can compare policy experiences, seek answers to common problems, identify good practice and work to co-ordinate domestic and international policies.

The OECD member countries are: Australia, Austria, Belgium, Canada, the Czech Republic, Denmark, Finland, France, Germany, Greece, Hungary, Iceland, Ireland, Italy, Japan, Korea, Luxembourg, Mexico, the Netherlands, New Zealand, Norway, Poland, Portugal, the Slovak Republic, Spain, Sweden, Switzerland, Turkey, the United Kingdom and the United States. The Commission of the European Communities takes part in the work of the OECD.

OECD Publishing disseminates widely the results of the Organisation's statistics gathering and research on economic, social and environmental issues, as well as the conventions, guidelines and standards agreed by its members.

This work is published on the responsibility of the Secretary-General of the OECD. The opinions expressed and arguments employed herein do not necessarily reflect the official views of the Organisation or of the governments of its member countries.

You can copy, download or print OECD content for your own use, and you can include excerpts from OECD publications, databases and multimedia products in your own documents, presentations, blogs, websites and teaching materials, provided that suitable acknowledgment of OECD as source and copyright owner is given. All requests for public or commercial use and translation rights should be submitted to rights@oecd.org. Requests for permission to photocopy portions of this material for public or commercial use shall be addressed directly to the Copyright Clearance Center (CCC) at info@copyright.com or the Centre français d'exploitation du droit de copie (CFC) at contact@cfcopies.com. 